\title{
Innovation in the New Model of Vocational Professional Teacher Education According to the Demands of the Industrial Revolution 4.0
}

\author{
Agus Setiawan*, R. Aam Hamdani \\ Department of Mechanical Engineering Education \\ Universitas Pendidikan Indonesia \\ Bandung, Indonesia \\ *agus_setiawan@upi.edu
}

\begin{abstract}
Vocational education is very important to prepare skilled workers for economic development. Quality vocational education is very much determined by quality of vocational teacher as well as quality of vocational professional teacher education. This paper addresses innovations in the new model of professional teacher education (PPG-Pendidikan Profesi Guru) in Indonesia. Data were collected through literature review, focus group discussion and interview with selected parties involved in PPG program. The following findings were obtained. Vocational professional teachers are prepared through PPG which is carried out at Teacher Education Institutes (LPTK) with a learning load of 38 credits for pre-service PPG and 12 credits for in-service PPG after implementation of RPL (recognition of prior learning). The PPG curriculum consists of 3 main courses, namely the Deepening of Pedagogical and content knowledges including advance materials, Development of Lesson Plan and Clinical Practicum at the partner schools. The new PPG model has the following innovations: (1) developing Higher Order Thinking Skills (HOTS) by using the Technological and Pedagogical Content Knowledge (TPACK) approach, (2) improving the sociocultural understanding of students and school environment. (3) Improving teacher competences and collaboration between supervisors and tutor teachers. (4) Improving the ability to reflect on learning. (5) Increasing leadership skills in learning. (6) Optimizing the use of ICT in PPG by applying blended learning system in PPG. These innovations are expected to be able to improve the quality of future vocational teachers in accordance with the demands of the industrial revolution 4.0.
\end{abstract}

Keywords-teacher, vocational, professional teacher education Introduction

\section{INTRODUCTION}

Recently TVET sector becomes more attractive because of the important role to economy development through preparing skilled workers. To improve TVET quality, Indonesian government has issued Presidential Instruction No. 9 year 2016 concerning Vocational School (SMK) Revitalization which aims to improve the quality of human resources for the nation's competitiveness [1]. Quality of vocational education is very much determined by the quality of teachers and trainers so that the development of vocational teachers is very important. Therefore, one of the SMK revitalization policies is to improve the quality of vocational teachers [2].

According to Teacher and Lecturer Law Number 15/2005, since 2015 professional teacher is only produced by PPG program conducted in appointed LPTK by government for one year [3]. In fact, up to now there are still many in-service teachers who have no professional teachers' certificate, so that they have to follow in-service PPG. In other side, there are issues that the competences of vocational student and teachers do not meet industry need. Most of the vocational teachers also have no expertise certificate from reputable certification body [4].

In line with the rapid change of technology, the phenomena of disruption along with the industrial revolution 4.0 requires various adjustments in education sector including development of vocational teacher competencies. Future teachers must be equipped with 21 st century skills and new literacy covering data literacy, technology literacy and humanity literacy [5]. To respond to the problems and challenges above, the Indonesian government is in the process of developing a new PPG model.

\section{Methodology}

This paper addresses innovations that have been made and future requirement for a new PPG model to respond industrial revolution 4.0. This research employs desktop research via literature review on PPG policies and implementation, followed by a Focus Group Discussion (FGD) and interview with selected respondents to complete and compare research data [6]. Focus of this study is policy and implementation of PPG system in Indonesia. The FGD was followed by 20 participants, and two keynotes speakers. They are representatives from The Ministry of Education and Culture of RI (MoEC), TVET experts, Teacher Education Institutes (LPTK), Vocational school (SMK), industries and local government (West Java Province). Because of covid-19 
pandemic, the FGD and interviews were carried out by using online platform with zoom cloud meeting.

\section{RESUlts AND DISCUSSION}

\section{A. Requirement of $21^{\text {st }}$ Century Skills for Industrial Revolution 4.0}

The disruption phenomenon in the era of IR 4.0 greatly affected education system including preparation of future teachers. These new skills, called the $21^{\text {st }}$ century skills, are needed for graduates to be able to compete in the world of work. According to some references, the $21^{\text {st }}$ Century Skills for IR 4.0 include, but not limited to: oral and written communication, problem solving, ethics and professionalism at work, teamwork and collaboration, using technology, project management and leadership, agility and adaptability, initiative and entrepreneurship, access, analyse and synthesize information, curiosity and imagination, productivity and accountability, innovative, global citizenship, higher order thinking [7-9]. This impacts on the need for new skills acquisition for teachers that should be included in professional teacher education program (PPG).

Because of disruption phenomena, the types of job currently exist will disappear to being replaced by robots and intelligent machine. About $65 \%$ of children entering primary school today will have a job that do not exist [10]. Changes with the adoption of IR 4.0 are as following: (1) Automated production (assembly lines to be equipped with robots, humanoids and machines). (2) Predictive maintenance (continuous machine monitoring and data analysis to reduce downtime). (3) Connected machines (machines connected over a network will coordinate to optimize production). (4) 3D Printing (manufacture complex parts in one-go without any assembly). (5) Big data (actions based on historical data to optimize production). (6) Smart transport system (automated transportation of raw material /final products). (7) Networked supply chain (monitoring and sharing data of complete supply chain). (8) Production simulation (simulation and optimization of production lines through software) [11]. Therefore, vocational education needs to prepare in order to adapt and be responsive against this development. Since vocational teacher is one of the pillars of vocational education, they have to be well prepared to meet IR 4.0.

The disruption phenomenon in the era of IR 4.0 greatly affected education system including preparation of future teachers. The new skills, called the $21^{\text {st }}$ century skills, are needed for graduates to be able to compete in the world of work. According to some references, the $21^{\text {st }}$ Century Skills for IR 4.0 include, but not limited to: oral and written communication, problem solving, ethics and professionalism at work, teamwork and collaboration, using technology, project management and leadership, agility and adaptability, initiative and entrepreneurship, access, analyse and synthesize information, curiosity and imagination, productivity and accountability, innovative, global citizenship, higher order thinking [7-9]. This impacts on the need for new skills acquisition for teachers that should be included in professional teacher education program (PPG).

\section{B. Status of Vocational Teachers Indonesia}

Indonesia has 14,157 SMK, consisting of 10,576 private SMK and 3582 Public SMK, with a total of 5,034,496 students. The data imply too many SMK and the ratio of students to teachers is too large. Big SMK (number of students higher than 1,000 students) have a significant role in fulfilling SMK services, where with only $9.01 \%$ from the total SMK they serve $36.29 \%$ of the total SMK students. Meanwhile, small SMK (number of students is less than 200 students) have no significant role, with more than half of the total number of SMK $(51.42 \%)$ which is only serve $13.31 \%$ of the total SMK students [12]. Indonesia is facing some problems with vocational teacher as following. Number of vocational teachers is still insufficient, especially for certain vocational teachers, i.e. maritime, textile, agriculture, renewable energy. Based on the teacher competence assessment, the competence of vocational teachers is still lacking which is shown by the average score lower than 60 (in 100 scale). Furthermore, vocational teachers are not evenly distributed throughout Indonesia. In addition, at present many vocational teachers do not have certificate of expertise and certificate of educator. The quality of professional Teacher Education carried out at Teacher Education Institute (LPTK) still needs to be improved significantly in term of lecturer, curriculum and quality assurance [13].

\section{Innovations in the New Model of PPG}

Education is a very valuable future investment. Therefore, the Indonesian government has committed that education for future generations must be well prepared. For this reason, the preparation of future generation must be followed by the preparation of professional teachers through a quality and accountable teacher education system.

According to Law Number 14 of 2005, teacher is professional educators with the main task of educating, teaching, guiding, directing, training, assessing, and evaluating students in early childhood education through formal education, primary education, and secondary education. Teachers are required to have academic qualifications, competencies, teacher certificates, be physically and mentally healthy, and be able to realize the goals of national education. Teacher certificates are given to teachers who have met the requirements [3]. The Professional Teacher Education also refers to some regulations on teachers [14], teacher education standards [15], and national higher education standards [16].

At present there are two new PPG models in Indonesia. The first model is in-service PPG for teachers who are already active in teaching but still do not have an educator certificate until 2015. This model is implemented with the consideration that there are still many in service teachers who do not have an educator certificate. According to the regulation, since 2015 an educator certificate can only be obtained through PPG. The second model is pre service PPG for S1 and D4 graduates who 
have not become teachers yet. PPG is implemented for one year with a learning load of 36-40 credits. PPG is carried out at the LPTK appointed by the government. For Pre-Service PPG, the learning load is 38 credits consisting of 3 courses, namely Deepening of Pedagogical and contents knowledges ( 2 credits), Development of lesson plan (12 credits) and Clinical Practicum (24 credits) [17]. For in-service PPG, the learning load is 12 credits after obtaining recognition of prior learning (RPL) of 24 credits. The courses consist of 3 subjects, namely deepening of pedagogical content knowledges (5 credits), Development of lesson plan ( 3 credits) and Clinical practicum (4 credits) [18]. Apart from being caused by the RPL, the difference weight of credits between in-service PPG and pre-service PPG is also caused by the different need of strengthening competence between the two, where in service teachers are relatively weak in mastery of pedagogic and content theory but have a lot of experiences in planning. And implementation of learning. Meanwhile, pre-service teacher candidate basically does not have experience in planning and implementing learning but relatively better in term of content knowledges.

A future teacher is expected to be able to carry out educational learning, master advanced materials according to their field and be able to integrate HOTS, be able to develop learning tools with the TPACK approach based on the RI 4.0 platform, conduct HOTS-based learning assessments and evaluations, and carry out Continuing Professional Development [17].

Based on literature review, FGD and interviews with selected key persons of PPG, implementation of the new model PPG include the following main stages $[17,18]$ :

- Entrance examination: Candidates of pre-service PPG are S1 or D4 graduate from the same and/or linear study program with the PPG program. The candidates must pass the online knowledge test. While Candidate of inservice PPG program are in-service teachers with at least 5 years of teaching experience and hold S1/D4 degree or teaching experience relevant to the proposed PPG program. The candidate have to follow online knowledge test and administrative test. The test was carried out by the PPG National Committee of the Ministry of Education and Culture of RI (MoEC).

- Registration; Candidate of the PPG program who have passed the exam have to register by online and report to the LPTK implementing PPG program.

- Conducting Lectures, which include the 3 courses: (1) Deepening of pedagogical and content knowledges (5 credits for in-service PPG and 2 credits for pre-service PPG), (2) Development of lesson plan (5 credits for inservice PPG and 4 credits for pre-service PPG), (3) Clinical practicum at partner school $(24$ credits for inservice PPG program and 4 credits for pre-service PPG program). Before doing the clinical practicum, PPG students have to follow a comprehensive test which is carried out in the form of an oral test including content, learning strategies, media, assessment from the three lesson plans that have been prepared before by the students.

- Final examination of PPG program which includes knowledge test and teaching performance test. The tests are carried out by the PPG National Committee of MoEC. The knowledge exam is a requirement for teaching performance test.

- Graduation as a professional teacher with an educator certificate.

From FGD and interviews, we found some innovation in a new pre-service and in-service PPG. In term of philosophy aspect, there is a reinforcement concept that PPG is an important instrument for human resource development. In addition, the new PPG model adopts the teachings of Ki Hajar Dewantoro where qualified teachers are obtained through input from prospective students, organizing LPTKs, curriculum and qualified lecturers and tutors. In this context there is a refresher program for prospective lecturers and tutors and improving the quality of the LPTKs. In addition, strengthening the education ecosystem is carried out through strengthening partnerships between PPG stakeholders which include the government, partner schools, LPTKs, communities and organizations that drive education and society. The new PPG model adopts, adapts and modifies the good experiences of PPG models in other countries.

The new PPG model is also in line with program of the Ministry of Education and Culture including: (1) Implementing the concept of independent learning in PPG, (2) Empowering of "Pancasila students" by strengthening literacy, numeracy and character education skills. In addition, the government is trying to increase the participation of the community in improving the quality of teacher education. The new PPG model also provides reinforcement in the aspects of teacher leadership in learning, the ability of teachers to reflect on learning and the ability of teachers to understand the sociocultural students and schools.

In the context of preparing future teachers in the era of the industrial revolution 4.0, innovations have been made to the new PPG model, including: (1) development of high order thinking skills (HOTS) which are integrated into teaching materials, learning processes and PPG assessments through additional advance materials. (2) Employing TPACK approach in teaching and learning.

In terms of learning platforms, the new PPG model is implemented by online platform due to the Covid-19 pandemic and as an effort to optimize the use of ICT in learning and education. PPG activities are carried out through Learning Management System (LMS) platform with synchronous and asynchronous combination learning modes.

\section{CONCLUSION}

We have studied the new model of pre service and inservice PPG in Indonesia. We have identified innovations in 
the new model to respond IR 4.0 as following: developing HOTS by using TPACK approach, improving the sociocultural understanding of students and school environment, improving teacher competences and collaboration between supervisors and tutor teachers, improving the ability to reflect on learning. Increasing leadership skills in learning and optimizing the use of ICT by implementing blended learning in PPG system. However, further innovation is still needed by considering future required competencies of vocational teachers.

\section{ACKNOWLEDGMENT}

The authors would like to thank to Universitas Pendidikan Indonesia (UPI) for financial support of this research through "Program Unggulan UPI" research scheme year 2020.

\section{REFERENCES}

[1] Presidential Instruction of the Republic of Indonesia Number 9 of 2016 concerning Revitalization of Vocational High Schools in the Context of Improving the Quality and Competitiveness of Indonesian Human Resources.

[2] Ministry of Education and Culture (MoEC) of Republic of Indonesia. Revitalization of Vocational Education. Jakarta, 2016.

[3] Law of the Republic of Indonesia Number 14 of 2005 concerning teachers and lecturers.

[4] Coordinating Ministry for the Economy (CMoE) of Republic of Indonesia. "Roadmap for Vocational Development Policies in Indonesia 2017-2025, 2017.
[5] J.E. Aoun, Robot-proof: higher education in the age of artificial intelligence. US: MIT Press, 2017.

[6] J.W. Creswell, Educational research: planning, conducting, and evaluating quantitative and qualitative research. New Jersey: Pearson Education Inc., 2009.

[7] T. Wagner, Overcoming The Global Achievement Gap. Cambridge, Mass: Harvard University, 2010.

[8] B. Trilling and C. Fadel, 21st Century Skills: Learning for Life in Our Times. San Francisco, Calif: Jossey-Bass/John Wiley \& US-based Apollo Education Group, 2009.

[9] M. Barry, What skills will you need to succeed in the future? Phoenix Forward. Tempe, AZ: University of Phoenix. Sons, Inc., 2012.

[10] World Economic Forum, "The Future of Jobs, Geneva," 2016.

[11] R. Berger, Skill Development for Industry 4.0. Global Skills Summit 2019. BRICS Skill Development Working Group, 2019.

[12] Ministry of Education and Culture (MoEC) of Republic of Indonesia, "Basic education data (Dapodik)," 2019.

[13] Ministry of Education and Culture (MoEC) of Republic of Indonesia Indonesia, "Building Indonesian Vocational Secondary Education: A Roadmap Towards 2030,” Jakarta, 2016.

[14] Government Regulation of Republic of Indonesia Number 19 of 2017 Regarding Amendments to Government Regulation Number 74 of 2008 concerning Teachers.

[15] Regulation of the Minister of Research, Technology and Higher Education of Republic of Indonesia Number 55 of 2017 concerning Teacher Education Standards.

[16] Regulation of the Minister of Education and Culture of Republic of Indonesia Number 3 of 2020 concerning National Higher Education Standards.

[17] Ministry of Education and Culture (MoEC) of Republic of Indonesia, "Pre-Service PPG Guidelines," Jakarta. 2020

[18] Ministry of Education and Culture (MoEC) of Republic of Indonesia, “ In-Service PPG Guidelines,” Jakarta, 2020. 